\title{
Propagação in vitro de Hypericum cordatum (Vell.) N. Robson (Clusiaceae) e análise fitoquímica de seus compostos secundários
}

BIANCHI, B.R.; CHU, E.P. *

Instituto de Botânica (SMA - SP), Av. Miguel Stéfano 3687, CEP: 04301-902, São Paulo-Brasil *chu07@ hotmail.com

RESUMO: Hypericum cordatum, planta com possível atividade medicinal foi analisada no presente estudo quanto a sua propagação in vitro e seus principais compostos secundários em comparação com Hypericum perforatum, espécie medicinal utilizada como antidepressivo. Diante das dificuldades que ocorrem na coleta e sua multiplicação por sementes ou via estacas caulinares, iniciou-se a propagação in vitro tendo como resultados: que a indução e o crescimento de brotações foram estimulados pelo regulador 6-benziladenina (2,0 $\left.\mathrm{mg} \mathrm{L}^{-1}\right)$, que houve indução de raízes por ácido indol-butírico $\left(0,5 \mathrm{mg} \mathrm{L}^{-1}\right)$, e que as baixas concentrações de

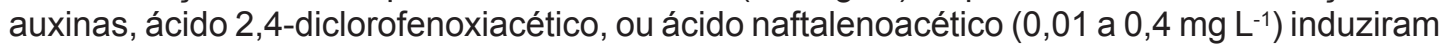
a formação de calos sendo uma alternativa viável para a multiplicação desta espécie in vitro. Constatou-se com base nas análises bioquímicas e cromatográficas realizadas nesta fase de desenvolvimento das plantas mantidas em culturas in vitro, que as mesmas não contêm hipericina. No entanto, pode-se atribuir o potencial medicinal de $\mathrm{H}$. cordatum às outras substâncias que também possuem importantes atividades biológicas, tais como a xantona e o ácido clorogênico sintetizados nas glândulas foliares de $H$. cordatum.

Palavras-chave: reguladores de crescimento, meio de cultura, antidepressivo

\begin{abstract}
In vitro propagation of Hypericum cordatum (Vell. Conc.) N. Robson (Clusiaceae) and phytochemical analysis of its secondary compounds. Hypericum cordatum, a plant with possible medicinal activity, was analyzed in this study for its in vitro propagation and main secondary compounds, compared to Hypericum perforatum, a medicinal species used as antidepressant. Considering the difficulties that occur in its collection and multiplication through seeds or stem cuttings, in vitro propagation was started and showed the following results: the induction and the growth of sprouts were stimulated by the plant regulator 6-benzyladenine $\left(2.0 \mathrm{mg} \mathrm{L}^{-1}\right)$, there was root induction by indolebutyric acid $\left(0.5 \mathrm{mg} \mathrm{L}^{-1}\right)$ and the low concentrations of auxins, 2,4-dichlorophenoxyacetic acid or naphthaleneacetic acid $\left(0.01\right.$ to $\left.0.4 \mathrm{mg} \mathrm{L}^{-1}\right)$ induced callus formation, constituting a viable alternative for the in vitro multiplication of this species. Biochemical and chromatographic analyses carried out at this developmental stage of plants kept in in vitro cultures indicated that they do not contain hypericin. However, the medicinal role of $H$. cordatum can be attributed to other substances that also have important biological activities, such as xanthone and chlorogenic acid, both synthesized in the leaf glands of $H$. cordatum.
\end{abstract}

Key words: growth regulators, culture medium antidepressant

\section{INTRODUÇÃO}

As plantas medicinais são extensivamente utilizadas em várias comunidades por séculos e, antes da moderna farmacologia, as doenças infecciosas ou contagiosas como varíola, sarampo, sífilis, tifo e hepatite eram letais devido à inexistência de tratamentos eficazes neste período (Chu, 2009). Com os remédios alopáticos e as vacinas, doenças causadas por bactérias, protozoários, vários vírus e inúmeras outras enfermidades crônicas são tratáveis.
Atualmente, tem-se a busca de compostos contra o câncer e os vírus, além de fármacos para artrite, distrofia muscular, obesidade, colesterol elevado, hipertensão, imunoestimulantes, antirrejeição, antimalária, agentes cardioativos e várias outras doenças induzidas por álcool, fumo, doenças do fígado e drogas-dependentes para a sociedade ocidental (Farnsworth \& Soejarto, 1991).

A família Clusiaceae possui diversos

Recebido para publicação em 20/12/2010

Aceito para publicação em 27/06/2012

Rev. Bras. PI. Med., Botucatu, v.15, n.1, p.25-33, 2013. 
compostos secundários com atividades biológicas, sendo que o gênero Hypericum possui 350 espécies em todo mundo, com alguns representantes descritos com atividade antisséptica, digestiva, expectorante, vermífuga (Corrêa, 1931; Cecchiniet al., 2007) e, principalmente da espécie cultivada comercialmente, Hypericum perforatum (L.), as ações: analgésica, anti-depressiva (Mans et al., 2000), antiviral (Takahashi et al., 1989), antifúngica (Fenner et al., 2005) e anticancerígena (VukovicGacic\&Simic, 1993; Schempp et al., 2002). Dentre as espécies nativas do Brasil já analisadas, extratos de $H$. brasiliense Choisy foram descritos com atividade antifúngica (Rocha et al., 1994), antibacteriana (Rocha et al., 1995; França et al., 2009) e sem atividade mutagênica (Espósito et al., 2005).

A espécie Hypericum cordatum (Vell.) N. Robson (Figuras 1A, 1C) é planta herbácea nativa, perene, heliófita e indiferente quanto às condições físicas do solo para cultivo (Lorenzi, 2002). Ocorre nos estados de Santa Catarina, Minas Gerais, São Paulo, Paraná e Rio Grande do Sul (Robson, 1981). Quando jovens, as partes aéreas apresentam coloração marrom avermelhada (Robson, 1981) e diferencia-se das outras espécies pelas folhas elípticas sésseis, oblongas ou triangular-lanceoladas, com margens inteiras e base subcordada, além de flores amarelo alaranjado de 0,5 a $1,5 \mathrm{~cm}$ de diâmetro (Figura 1B) que florescem e frutificam de outubro a maio (Slusarskiet al., 2007). A altura varia de 0,2 a $0,6 \mathrm{~m}$, possui o caule ramificado desde a base ou acima desta e suas sementes têm entre 0,8 e 1,0 mm de comprimento, o que dificulta sua coleta e propagação sexuada (Robson, 1981; Slusarski et al., 2007).

As plantas desta espécie são amplamente distribuídas no campo onde crescem e, diferentemente do $H$. brasiliense, é bianual, tendo o ciclo de vida curto, no qual a planta morre após o surgimento dos frutos e a dispersão das sementes. Este fato pode indicar que $\circ \mathrm{H}$. cordatum origine um banco de sementes no solo após a floração e formação de frutos. Deste modo, seria gerada uma nova população de $H$. cordatum a cada ciclo de chuvas, entre os meses de outubro e novembro, justificando assim o fato de ter sido encontrada população em plena floração entre os meses de coleta, fevereiro e abril, e nenhum exemplar até o mês de setembro (Moraes, 2007).

Hypericum perforatum (nome popular erva-de-são-joão, hipérico) é a espécie de maior importância medicinal deste gênero, tendo sido seu princípio ativo, a hipericina, estudado ainda na Idade Média devido ao odor das glândulas de coloração rósea em suas flores amarelas com as quais são feitas o chá ou a infusão (Tray, 2007). Atualmente é utilizado também nos tratamentos neurológicos, gastrites e anti-inflamatórios (Tray, 2007). Seu principal uso é na ação antidepressiva do sistema nervoso central, além do grande potencial ornamental, devido a suas belas inflorescências (Lorenzi, 2002). Esta antraquinona também é bactericida, potente antiviral (Cardoso, 1996), sedativa (Pretto, 2000), analgésica, calmante do sistema nervoso, amenizando tosses, cefaléias e dores reumáticas, além de seu uso interno na forma de decocção contra ansiedade, não sendo recomendada para pacientes com depressão crônica (Kumar et al., 2010).

Suzukiet et al. (1984) descreveram a hipericina como inibidora da monoamino-oxidase (MAO), importante enzima relacionada com distúrbios neuropsiquiátricos, porém estudos posteriores mostraram que a hipericina tratava-se de um inibidor fraco ou não inibidor de MAO. Além disso, existem indicações de que as concentrações necessárias de hipericina para obtenção de atividade biológica
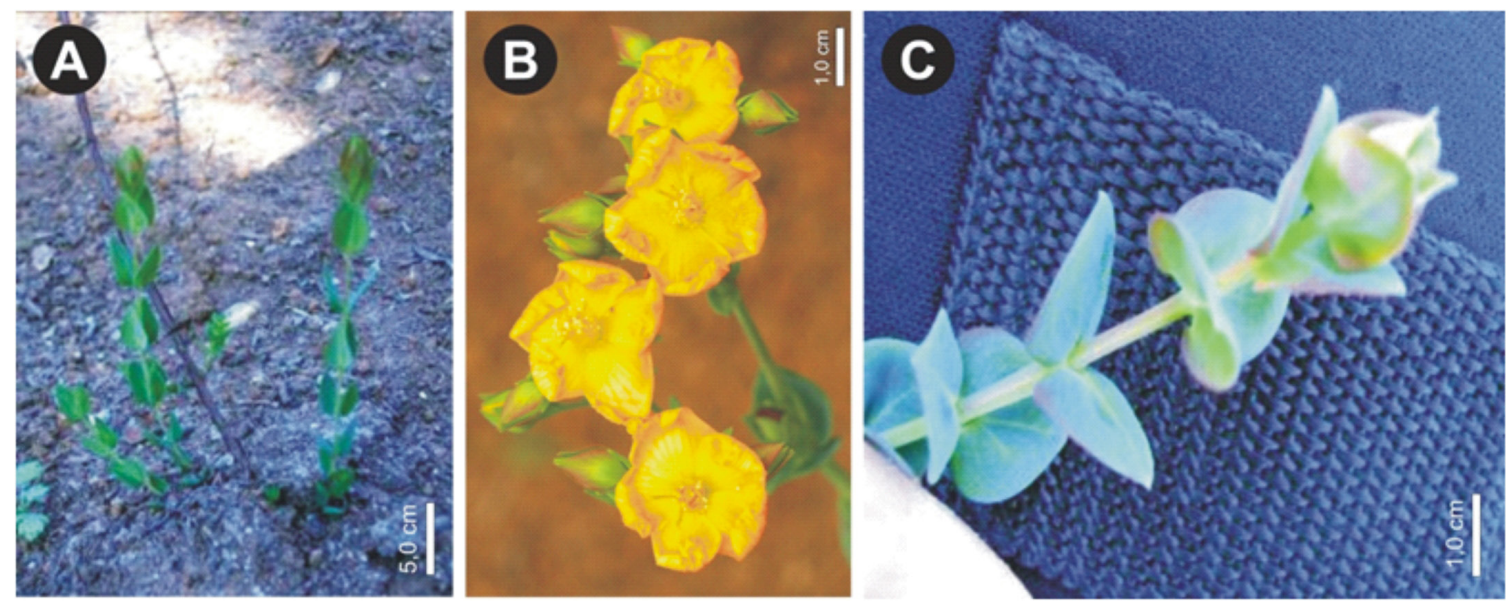

FIGURA 1. Hypericum cordatum cultivado em canteiro de propagação: (A) aspecto geral; (B) detalhes das flores; (C) detalhe do ápice caulinar. 
dificilmente seriam atingidas após administração oral de preparados de Hypericum perforatum (Barneset al., 2001) sendo o efeito antidepressivo desta espécie provavelmente devido ao sinergismo de diversos compostos secundários acumulados nas glândulas oleíferas como os encontrados em $H$. cordatum (Figura 2A.). Extratos metanólicos de outras espécies brasileiras, inclusive $H$. cordatum, não demonstraram atividade antidepressiva no teste de esforço de natação em ratos Wistar (Gnerre et al., 2001).

Além da hipericina, os principais compostos secundários encontrados em Hypericum são flavonóides, como quercetina e rutina, cujas atividades biológicas são antiviral e redutora do estresse oxidativo para a primeira, vasoprotetor capilar, para a segunda, e antioxidante para ambas (Dias, 2005; Cecchini et al., 2007; Bezzera, 2009), além da xantona, sendo ela antifúngica, antidepressiva, mutagênica e antiinflamatória (Dourado, 2008). Outra classe é a dos polifenóis, como o ácido clorogênico, com as possíveis atividades anticarcinogênica e preventiva do estrese oxidativo (Garambone \& Rosa, 2007) e das próprias antraquinonas, como a hiperforina, de ação antidepressiva (Barnes et al., 2001; Falkenberg, 2001).

O objetivo do trabalho foi estabelecer o protocolo de propagação in vitro de Hypericum cordatum (Vell.) N. Robson utilizando diferentes balanços de reguladores de crescimento vegetal (auxinas e citocininas), além de diferentes concentrações de sacarose e tirosina, bem como o monitoramento dos compostos secundários de $H$. cordatum por cromatografia em camada delgada em comparação com amostras autênticas de $H$. perforatum.

\section{MATERIAL E MÉTODOS}

\section{Micropropagação}

As plantas de Hypericum cordatum foram coletadas em campo aberto, na beira de estrada (Rodovia SP-250, km 63), no município de Ibiúna (São Paulo) e cultivadas em canteiro de propagação no Núcleo de Fisiologia e Bioquímica de Plantas do Instituto de Botânica (Secretaria do Meio Ambiente do Governo do Estado de São Paulo; Voucher Number Cordeiro 1702 SP, Herbário Científico do Estado "Maria Eneyda P. Kauffmann Fidalgo", Instituto de Botânica, São Paulo - Brasil). Os fragmentos vegetais (gemas apicais, folhas, nós e entrenós) foram inoculados in vitro, sendo que somente os ramos axilares (nós) foram adequados para a multiplicação em cultura de tecidos, resistindo à etapa de desinfestação, sendo induzidos à propagação de gemas in vitro.

A desinfestação do explante foi realizada com lavagem em água corrente durante 30 minutos com duas gotas de detergente comercial, seguida por esterilização superficial com etanol $80 \%$ por 90 segundos, duas lavagens com água destilada estéril, nova desinfestação superficial com hipoclorito de sódio ( $2,5 \%$ de cloro ativo) por 10 minutos, seguido de mais cinco lavagens com água destilada estéril e, já em ambiente asséptico, foram inoculados em meios de cultura. Os explantes foram inoculados em meios de cultura Murashige \& Skoog - MS (1962) completo com 3,0\% de sacarose, $0,85 \%$ de ágar comercial e pH ajustado para 5,8 . Todos os meios de cultura foram esterilizados em autoclave à $121^{\circ} \mathrm{C}(1,2 \mathrm{~atm})$ por 25 minutos. As culturas in vitro foram realizadas em frascos de vidro (capacidade de $300 \mathrm{~mL}$, com $80 \mathrm{~mL}$ de meio de cultura, tampa de polipropileno e 10 repetições por tratamento) e mantidas em salas de ambiente controlado com iluminação artificial (lâmpadas fluorescentes e incandescentes fornecendo $32 \mathrm{mmol} \mathrm{m}^{-2} \mathrm{~s}^{-1}$ de fluxo de fótons fotossintéticos) com fotoperíodo de 16 horas e temperatura de $25 \pm 1^{\circ} \mathrm{C}$. Todos reagentes, sais e solventes utilizados foram grau pró-análise.

Inicialmente foram realizados os tratamentos com os meios M7, AGO H, carvão ativado, ANA, Ouro Verde, Vh-Out, AIB (Tabela 1), onde os melhores explantes foram selecionados para a fase de indução de raízes e aclimatação em tratamentos com diferentes reguladores de crescimento.

Para o experimento inicial foram utilizados alguns destes tratamentos para a multiplicação, observação dos resultados e posteriormente para induzir o enraizamento. Para tanto foram utilizados reguladores vegetais sintéticos do tipo auxina, para desenvolvimento de raízes (ácido 2,4-diclorofenoxiacético, ácido naftalenoacético e ácido indol-butírico) e citocinina, para desenvolvimento da parte aérea (6-benzilaminopurina e cinetina). Para a indução e incremento na produção de compostos secundários, foram realizados tratamentos em explantes de culturas com tirosina, um aminoácido percursor com maior disponibilidade de fonte de carbono sacarose, e com caseína hidrolisada, que aumenta a disponibilidade de nitrogênio.

As características observadas no desenvolvimento em cultura de tecidos foram comparadas entre os tratamentos (análise de variância simples, 10 repetições com o mínimo de 12 explantes por frasco, transformados em percentagem), sendo elas: a indução e número de gemas, a indução e número de raízes, a indução de calos e a cor inicial (verde, avermelhado ou caramelo - início de senescência) e a produção de folhas (fonte das glândulas oleíferas para síntese de compostos

Rev. Bras. PI. Med., Botucatu, v.15, n.1, p.25-33, 2013. 
TABELA 1. Tratamentos realizados em cultura in vitro de Hypericum cordatum.

\begin{tabular}{|c|c|c|}
\hline Tratamento & Composição & Objetivo \\
\hline M7 & $\begin{array}{l}\left.\text { MS 1/2 (metade da concentração dos sais); 6-BA (0,1 à } 8,0 \mathrm{mg} \mathrm{L}^{-1}\right) ; 2,4-\mathrm{D} \\
\left(0,0005 \text { à } 0,4 \mathrm{mg} \mathrm{L}^{-1}\right) ; \text { sacarose } 3 \%\end{array}$ & $\begin{array}{l}\text { Diferenciação e } \\
\text { multiplicação }\end{array}$ \\
\hline AGO H & MS 1/2; 6-BA (1,0 mg L-1); 2,4-D (0,02 $\left.\mathrm{mg} \mathrm{L}^{-1}\right) ;$ sacarose $2 \%$ & $\begin{array}{l}\text { Diferenciação e } \\
\text { multiplicação }\end{array}$ \\
\hline $\begin{array}{l}\text { ANA e } \\
\text { fertilizante } \\
\text { comercial }\end{array}$ & Fertilizante comercial Ouro Verde $2,0 \mathrm{~g} \mathrm{~L}^{-1}$; ANA $10,0 \mathrm{mg} \mathrm{L}^{-1}$; sacarose $2 \%$ & $\begin{array}{l}\text { Enraizamento e redução } \\
\text { de custos }\end{array}$ \\
\hline Vh-Out & $\begin{array}{l}\text { MS completo; 6-BA }\left(0,32 \mathrm{mg} \mathrm{L}^{-1}\right) ; \mathrm{K}\left(0,32 \mathrm{mg} \mathrm{L}^{-1}\right) ; \text { ANA 0,004 mg L-1; } \\
\text { sacarose } 4 \%\end{array}$ & $\begin{array}{l}\text { Diferenciação e } \\
\text { multiplicação }\end{array}$ \\
\hline AlB & MS 1/2; 2,4-D (0,02 mg L-1);AIB 0,5; 1,0 e 2,0 mg L-1; sacarose $2 \%$ & Enraizamento \\
\hline tirosina & $\begin{array}{l}\text { MS completo, MS } 1 / 2 \text { e MS } 1 / 4 ; \text { com tirosina }\left(50,0 \mathrm{mg} \mathrm{L}^{-1}\right) \text { e sem tirosina; } \\
\text { sacarose } 3 \%\end{array}$ & $\begin{array}{l}\text { Incremento na produção } \\
\text { de compostos secundários }\end{array}$ \\
\hline AIB 3,0 e $6-B A$ & MS completo; AIB 3,0 mg L-1; 6-BA 0,32 mg L-1; sacarose $4 \%$ & $\begin{array}{l}\text { Enraizamento e } \\
\text { aclimatação }\end{array}$ \\
\hline sacarose & MS completo; AIB 2,0 mg.L-1; 6-BA 0,1 mg L-1; sacarose $(2,4$ e $6 \%)$ & $\begin{array}{l}\text { Enraizamento e indução } \\
\text { de compostos secundários }\end{array}$ \\
\hline $\begin{array}{l}\text { Casein } \\
\text { hidrolizada }\end{array}$ & $\begin{array}{l}\text { MS completo; AIB 2,0 mg L-1; 6-BA 0,1 mg L-1; sacarose } 4 \% \text {; caseína } \\
\text { hidrolizada } 1 \%\end{array}$ & $\begin{array}{l}\text { Enraizamento e } \\
\text { incremento de compostos } \\
\text { secundários }\end{array}$ \\
\hline
\end{tabular}

Abreviaturas: MS - meio de cultura Murashige\&Skoog (1962); 6-BA - 6-benziladenina; 2,4-D - ácido 2,4-diclorofenoxiacético; ANA - ácido naftaleno-acético; AIB - ácido indol-butírico; K - cinetina

secundários). Plantas desenvolvidas in vitro, com caules e raízes, foram selecionadas para a fase de aclimatação após cuidadosa limpeza dos explantes, com a retirada do meio de cultura e transferência para substrato previamente tratado (vermiculita expandida média hidratada com solução de adubo foliar solúvel comercial e esterilizada em autoclave por 30 minutos). As plantas foram cultivadas sob cobertura plástica transparente (PVC), pulverizadas duas vezes ao dia com água destilada e o substrato mantido sempre em alta umidade até o surgimento de novas raízes.

\section{Extração e análise fitoquímica}

Os extratos etanólicos dos explantes de $H$. cordatum cultivados in vitro e de $H$. perforatum (cápsula fitoterápica e sumidades florais para chá) foram preparados do material vegetal seco ou do liofilizado, sendo triturados em almofariz, extraídos com etanol $80 \%$ (três vezes), centrifugados (15 minutos, $125 \mathrm{~g}$ a temperatura ambiente) para retirada e reunião da fase etanólica, concentrados dos respectivos extratos sob pressão reduzida, despigmentados com partição líquido-líquido (solvente hexano -três extrações) e ajustados os volumes. A determinação química foi realizada em espectrofotômetro UV-VIS com leituras em 450 e $588 \mathrm{~nm}$ (Nait-Si\&Fourneron, 2004), tendo como padrão cápsulas de Hypericum perforatum (300,0 mg de extrato vegetal por cápsula com teor indicado de $3,0 \%$ de hipericina).

As análises cromatográficas foram realizadas em placas de alumínio com sílica gel $60 \mathrm{GF}_{254}$ de 0,2 $\mathrm{mm}$ de espessura (tamanho $20 \mathrm{x}$ $20 \mathrm{~cm}$ - Merck), com pré-lavagem com solvente de corrida (tolueno, acetato de etila e ácido fórmico $50: 40: 10, v / v / v$ - Mulinacci et al., 1999) seguida de secagem e ativação da placa $\left(120^{\circ} \mathrm{C}\right.$ por 30

Rev. Bras. PI. Med., Botucatu, v.15, n.1, p.25-33, 2013. 
minutos). Volumes conhecidos de cada amostra etanólica bem como diversos padrões autênticos de compostos secundários vegetais (X - xantona, $A C$ - ácido clorogênico, $Q$-quercetina, $R$ - rutina) foram co-cromatografados nas placas (mesmo solvente de corrida descrito acima com 30 minutos de desenvolvimento), possibilitando estabelecer o tempo de retenção de cada substância e a coloração sob luz natural (visível) e ultravioleta (254 e 273 $\mathrm{nm}$ ). Por comparação direta destes dados, inferiuse a presença destes compostos nas amostras de $H$. cordatum e $H$. perforatum. A hipericina $(H)$ existente nos extratos de Hypericum perforatum (cápsula e chá comercial) foi considerada padrão de comparação com as amostras de H. cordatum.

\section{RESULTADO E DISCUSSÃO}

Explantes de $H$. cordatum inoculados nos tratamentos apresentaram grande produção de gemas de pequeno tamanho (Figuras 2B, 2C, 2D), caules, algumas ramificações, folhas de menor tamanho, quando comparadas com as cultivadas em canteiro, e raramente flores.

Os tratamentos que mostraram melhores resultados foram: AIB $\left(0,5 ; 1,0\right.$ e 2,0 $\left.\mathrm{mg} \mathrm{L}^{-1}\right)$ onde foi observado que, com a concentração de $0,5 \mathrm{mg} \mathrm{L}^{-1}$ em 3 frascos, 1 apresentou 5,26\% e 2 apresentaram $6,67 \%$ de enraizamento. O tratamento M7 $(0,32$ $\mathrm{mg} \mathrm{L}^{-1}$ de 6-BA e 0,0016 $\mathrm{mg} \mathrm{L}^{-1}$ de 2,4-D), tirosina e AIB (3,0 mg L-1) com 6-BA $\left(0,32 \mathrm{mg} \mathrm{L}^{-1}\right)$ para o desenvolvimento de inúmeros caules curtos e agrupados, folhas de pequeno comprimento com glândulas oleíferas visíveis, calos verdes na base do caule em contato com o meio de cultura e algumas raízes, sem diferença estatística entre os tratamentos realizados.

$\mathrm{O}$ meio AGO H induziu a formação de inúmeras pequenas gemas e calos devido à presença de ácido 2,4-diclorofenoxiacético. Os tratamentos de ANA $\left(10,0 \mathrm{mg} \mathrm{L}^{-1}\right)$ e fertilizante comercial, Vh-Out foi completamente inviável ao explante, ocasionando a perda de todos os explantes devido ao processo de senescência. Os
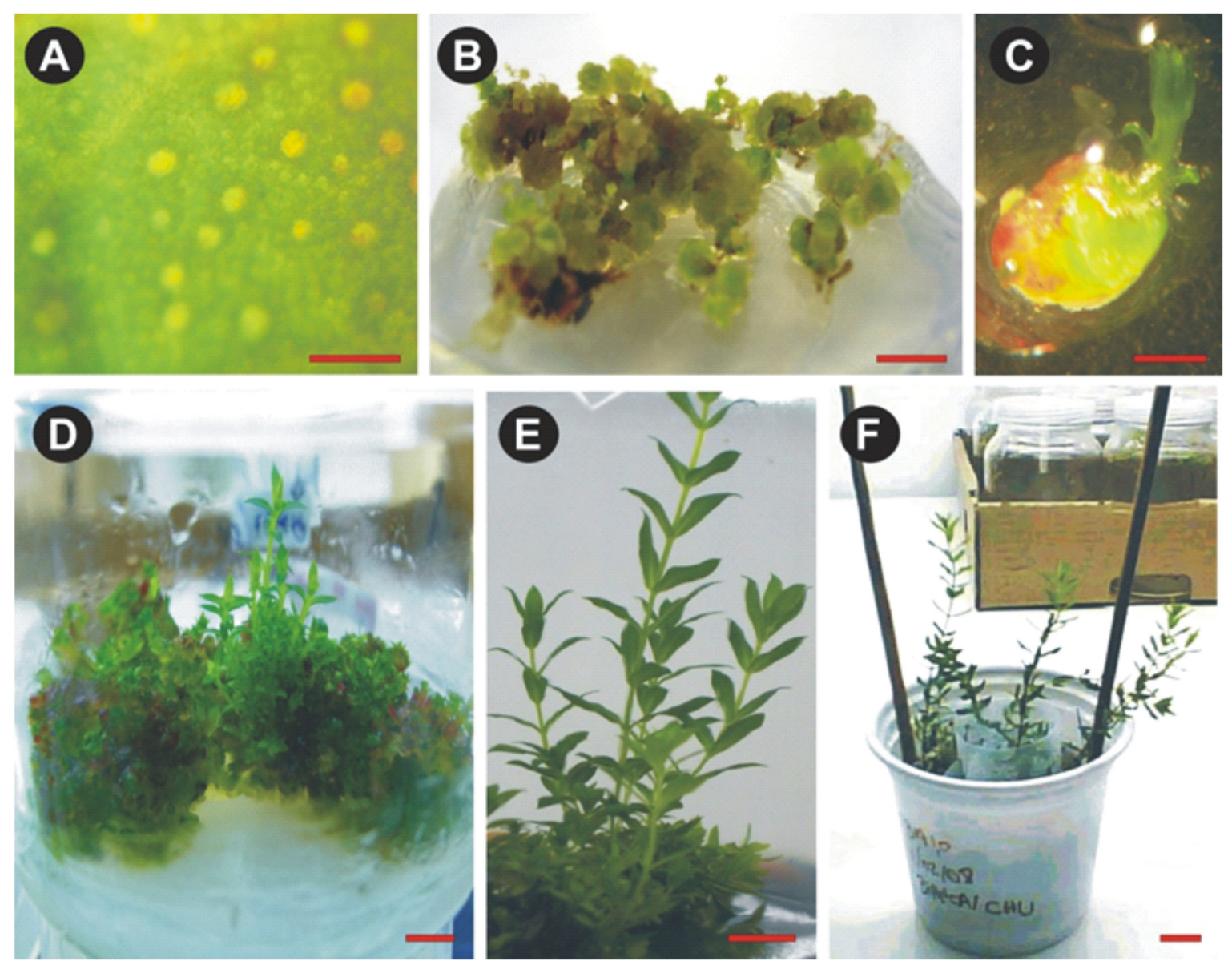

FIGURA 2. Hypericum cordatum: (A) glândulas oleíferas foliares de plantas cultivadas em canteiro de propagação; (B) brotações mantidas em cultura de tecidos; (C) detalhe de broto in vitro; (D) aspecto geral de propagação in vitro; (E) brotações após 40 dias de desenvolvimento; e (F) fase de aclimatação; barras de A, B e C = 0,5 $\mathrm{cm}$ e barras de $\mathrm{D}, \mathrm{E}$ e $\mathrm{F}=1,0 \mathrm{~cm}$. 
demais tratamentos (sacarose, caseína hidrolizada e outros meios de M7) apresentaram resultados intermediários na indução e crescimento de gemas, pouca produção de raízes e grande crescimento de calos. Para o ensaio feito com tirosina e sacarose, obteve-se os resultados de $11,11 \%, 60 \%$ e $100 \%$ para os frascos onde não foram adicionados tirosina e tiveram concentrações de 100\%, 50\% e $25 \%$ de sacarose, respectivamente, e, para os que foram adicionados $50 \mathrm{mg} \mathrm{L}^{-1}$ de tirosina, com as mesmas concentrações respectivas de sacarose, os resultados foram $0 \%, 0 \%$ e $22,22 \%$ de enraizamento. A sacarose em experimentos com concentrações de $2 \%, 4 \%$ e $6 \%$ induziu a formação de glândulas oleíferas, sendo observadas respectivamente 4, 2 e 2 glândulas em cada frasco contendo aproximadamente a mesma quantidade de explantes.

Os maiores caules com indução de raízes dos tratamentos M7, AGO-H, ANA, Vh-Out e AIB foram transferidos para potes com vermiculita para aclimatação. Das vinte plantas selecionadas, apenas duas produziram novas raízes e foram transferidas para novos vasos para crescimento em casa de vegetação.

Diferentes explantes de $H$. cordatum cultivados in vitro e $H$. perforatum (cápsulas de fitoterápico) foram utilizados na análise cromatográfica (Tabela 3). Para a curva padrão de hipericina com leitura a $450 \mathrm{~nm}$, a regressão linear foi $x=y / 0,1187\left(R^{2}=0,9755\right)$ e a $588 \mathrm{~nm}, x$ = y / 0,1677 $\left(R^{2}=0,9326\right)$, apresentado correlação direta entre a leitura obtida na espectrofotometria e a concentração do padrão de hipericina analisado.

Os extratos etanólicos de alguns tratamentos de $H$. cordatum foram submetidos à análise bioquímica de hipericina, com explantes desenvolvidos em meio MS: sem nenhum tratamento de regulador de crescimento, amostras com contaminação acidental por fungos (com consequente produção de compostos secundários de defesa), outros tratamentos contaminados, e com outros reguladores vegetais (Tabela 2 ).

Observa-se que alguns tratamentos apresentaram maior concentração de equivalentes de hipericina nas plantas in vitro de $H$. cordatum devido à contaminação acidental das culturas (MS completo - não contaminado e tratamento 6-BA / K ( ANA - contaminado), possivelmente aumentando a quantidade dos compostos secundários como mecanismo de defesa, chegando o valor de hipericina no tratamento somente com MS contaminado, a mais de 10 vezes do valor encontrado no controle (MS sem contaminação). As diferentes concentrações de equivalentes de hipericina obtidos nas leituras de $450 \mathrm{~nm}$ e $588 \mathrm{~nm}$, específicos para o composto secundário em consideração, indicam outros compostos secundários existentes nos extratos etanólicos dos explantes cultivados in vitro que podem absorver a luz incidente de 450 e, ou, 588 $\mathrm{nm}$ do espectrofotômetro.

As análises realizadas em cromatografia de camada delgada possibilitam a identificação das substâncias presentes nas plantas cultivadas in vitro de $\mathrm{H}$. cordatum e nas amostras fitoterápicas de $H$. perforatum, bem como a comparação direta com padrões autênticos de vários compostos secundários vegetais pelo tempo de retenção e coloração das substâncias sob iluminação natural (Figura 3).

As amostras etanólicas e em chá de $H$. perforatum apresentaram ácido clorogênico, quercetina, rutina, e hipericina, não sendo identificada xantona; já nas amostras de $H$. perforatum em cápsulas, foram identificados rutina e hipericina estando ausentes o ácido clorogênico, quercetina e xantona; todas as substâncias já foram descritas em literatura. As amostras de $H$. cordatum apresentaram

TABELA 2. Equivalente de hipericina ( $\mu \mathrm{g}^{-1}$ de massa seca de Hypericum cordatum cultivado in vitro) observada em duas faixas de comprimento de onda (450 e 588nm).

\begin{tabular}{|c|c|c|c|c|c|}
\hline \multirow{2}{*}{$\begin{array}{l}\text { Origem da amostra } \\
\text { de Hypericum cordatum } \\
\text { Cultivado in vitro }\end{array}$} & \multirow{2}{*}{$\begin{array}{l}\text { Massa } \\
\text { fresca } \\
(\mathrm{g})\end{array}$} & \multirow{2}{*}{$\begin{array}{l}\text { Massa } \\
\text { seca } \\
(\mathrm{g})\end{array}$} & \multirow{2}{*}{$\begin{array}{c}\text { Massa } \\
\text { seca } \\
(\%)\end{array}$} & \multicolumn{2}{|c|}{$\begin{array}{l}\text { equivalente de hipericina } \\
\text { ( } \mu \mathrm{g} \mathrm{g}^{-1} \text { massa seca) }\end{array}$} \\
\hline & & & & $450 \mathrm{~nm}$ & $588 \mathrm{~nm}$ \\
\hline MS completo (sem contaminação) & 22,73 & 1,45 & 6,38 & 133,3 & 48,2 \\
\hline MS completo - contaminados em 26/11/2007 & 1,82 & 0,33 & 18,12 & 1272,3 & 562,5 \\
\hline \multicolumn{6}{|l|}{ MS 1/2; 2,4-D (0,02 mg L-1); AIB 1,0 e } \\
\hline $2,0 \mathrm{mg} \mathrm{L}^{-1}$ de $28 / 11 / 2007$ & 7,11 & 0,88 & 12,37 & 654,1 & 199,5 \\
\hline \multicolumn{6}{|l|}{ MS 1/2; 6-BA (1 mg L-1 $) ; 2,4-D\left(0,02 \mathrm{mg} \mathrm{L}^{-1}\right)$} \\
\hline contaminados em 08/11/2007 & 1,50 & 0,11 & 7,34 & 19,5 & 10,7 \\
\hline \multicolumn{6}{|c|}{ 6-BA $\left(0,32 \mathrm{mg} \mathrm{L}^{-1}\right) ; \mathrm{K}\left(0,32 \mathrm{mg} \mathrm{L}^{-1}\right) ;$ ANA $0,004 \mathrm{mg} \mathrm{L}^{-1}$} \\
\hline contaminado em 08/11/2007 & 3,06 & 0,42 & 13,74 & 544,5 & 105,9 \\
\hline
\end{tabular}

Rev. Bras. PI. Med., Botucatu, v.15, n.1, p.25-33, 2013. 


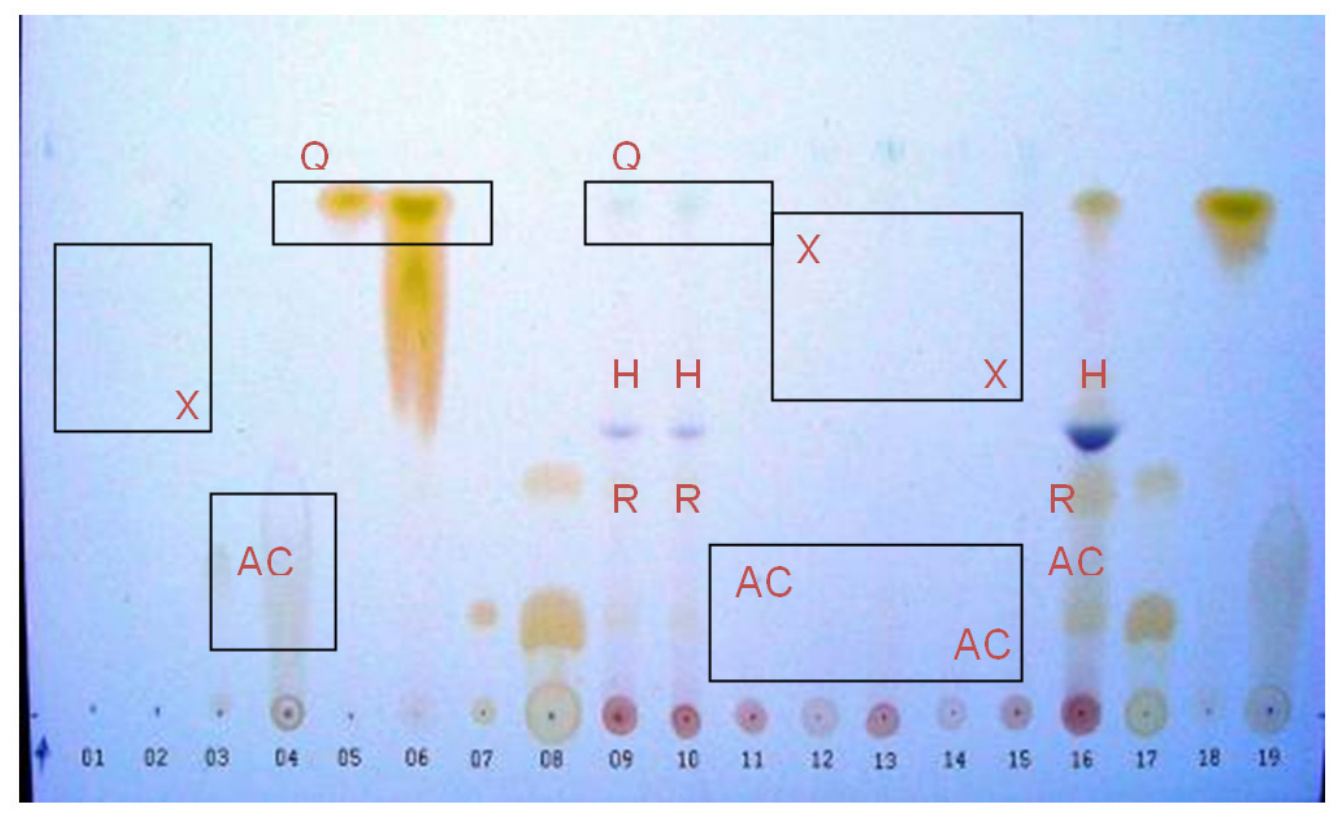

Amostra (quantidade amostrada)
Amostra (quantidade amostrada)
9- Hypericumperforatum em cápsula $(5 \mu \mathrm{L})$
10-Hypericumperforatum em cápsula $(5 \mu \mathrm{L})$
11- Hypericumcordatum sem contaminação $(5 \mu \mathrm{L})$
12- Hypericumcordatum contaminado ( $5 \mu \mathrm{L})$
13- Hypericumcordatum contaminado AIB $(5 \mu \mathrm{L})$
14- Hypericumcordatum contaminado 2,4-D $(5 \mu \mathrm{L})$
15- Hypericumcordatum contaminado ANA $(5 \mu \mathrm{L})$
16- Hypericumperforatum em chá comercial $(5 \mu \mathrm{L})$
17 - rutina $(0,10 \mathrm{mg})$
18- quercetina $(0,10 \mathrm{mg})$
19- ácido clorogênico $(0,10 \mathrm{mg})$

FIGURA 3. Cromatoplaca dos compostos secundários de Hypericum perforatum, de Hypericum cordatum e padrões de compostos secundários vegetais observados em luz natural após desenvolvimento em tolueno acetato de etila - ácido fórmico (50:40:10, v/v/v) por 30 minutos.

xantona e ácido clorogênico (Figura 3 - não visível na fotografia digital), além de outros compostos em menor concentração, ainda não identificados, e ausentes os compostos secundários quercetina, rutina e hipericina.

H. cordatum pode ser propagado in vitro a partir de explantes nodulares utilizando diferentes balanços de reguladores de crescimento vegetal para indução de brotos, calos e raízes. A partir dos resultados obtidos, conclui-se que o crescimento das gemas foi estimulado pelo regulador $6-B A(2,0$ $\left.\mathrm{mg} \mathrm{L}^{-1}\right)$, que a indução de raiz foi estimulada pelo AIB $\left(0,5 \mathrm{mg} \mathrm{L}^{-1}\right)$, e que baixas concentrações das auxinas 2,4-D e ANA $\left(0,01\right.$ a $\left.0,4 \mathrm{mg} \mathrm{L}^{-1}\right)$ induzem a formação de calos. A propagação in vitro mostrouse uma alternativa viável para a multiplicação desta espécie em função de seu crescimento, propagação e desenvolvimento de todas as partes vegetativas, inclusive algumas flores.

As análises dos compostos secundários dos extratos etanólicos e a sua identificação em cromatografia em camada delgada apresentaram como principais componentes: o ácido clorogênico, presente tanto em $H$. cordatum e $H$. perforatum, além da xantona, identificada somente em $H$. cordatum. Quercetina, rutina e hipericina, principal composto de interesse farmacológico, foram identificados nas amostras comerciais de $H$. perforatum, tanto em cápsulas fitoterápicas como em produtos para preparo de chás.

Os extratos etanólicos de $H$. cordatum não apresentaram o composto secundário hipericina nas análises cromatográficas quando comparadas com os padrões de $H$. perforatum.

Com base nestas análises e comparando as duas espécies de Hypericum, pode-se atribuir a atividade biológica do $H$. cordatum, nesta fase de desenvolvimento da planta, não à hipericina, que não foi observada nas culturas, mas às outras substâncias que também possuem importantes atividades biológicas, tais como a xantona e o ácido clorogênico identificadas nos explantes cultivados in vitro. A pesquisa indica a necessidade de mais estudos sobre esta planta e as interações de seus 
compostos secundários, bem como a caracterização fitoquimica em outros estádios da planta.

\section{AGRADECIMENTO}

Nossos agradecimentos à Dra Ângela Maria Ladeira pelo fornecimento de material vegetal inicial, ao programa PIBIC - CNPq / Instituto de Botânica - Secretaria de Meio Ambiente (Gov. Estado de São Paulo) pela bolsa de Iniciação Científica e à Faculdade de Ciências da Saúde (Monografia de Conclusão de Curso).

\section{REFERÊNCIA}

ABREU, I.N. et al. Distribution of bioactive substances from Hypericum brasiliense during plant growth. Plant Science, v.167, p.949-54, 2004.

BARNES, J. et al. Effect of St. John's worth (Hypericum perforatum): A review of chemistry, pharmacology and chemical properties. Journal of Pharmacy and Pharmacology, v.53, p.583-600, 2001.

BEZERRA, A.S. Caracterização de compostos antioxidantes em grãos de diferentes cultivares de cevada (Hordeum vulgare L.). 2009. 108p. Dissertação (Mestrado)-Universidade Federal de Santa Maria, Centro de Ciências Rurais, Programa de Pós-Graduação em Ciência e Tecnologia dos Alimentos, Santa Maria.

CARDOSO, M.A.; OLIVEIRA, D.E. Tissue culture of Hypericum brasiliense Choisy: shoot multiplication and callus induction. Plants Cell, Tissue and Organ Culture, v.44, p.91-4, 1996.

CECCHINI, C. et al. Antimicrobial activity of seven Hypericum entities from central Italy. Planta Medica, v.73, n.6, p.564-6, 2007.

CHU, E.P. Plantas com potencial medicinal. In: LOPES, M.I.M.S. et al. (Orgs.). Patrimônio da reserva biológica do Alto da Serra de Paranapiacaba: a antiga estação biológica do Alto da Serra. São Paulo: Instituto de Botânica, 2009, p.412-39.

ÇIRAK, C. et al. Secondary metabolites in Hypericum perfoliatum: variation among plant parts and phenological stages. Botanica Helvetica, v.117, p.29-36, 2007a.

ÇIRAK, C. et al. Variation of bioactive secondary metabolites in Hypericum origanifolium during its phenological cycle. Acta Physiologiae Plantarum, v.29, p.197-203, 2007b.

CORREAA, M.P. Dicionário das plantas úteis do Brasil e das exóticas cultivadas. Rio de Janeiro: Ministério da Agricultura/IBDF, v.1-6, 1931.

DIAS, A.S. $O$ antioxidante quercetina diminui o estresse oxidativo hepático em ratos diabéticos. 2005. 120p. Tese (Doutorado- Área de Concentração em Fisiologia)Instituto de Ciências Básicas da Saúde, Universidade Federal do Rio Grande do Sul, Porto Alegre.

DOURADO, R. S.; LADEIRA, Â. M. Identificação de flavonóides em Hypericum cordatum (Vell.) N. Robson (Clusiaceae). Revista Brasileira de Botânica, vol.31, n.4, p. 611-20, 2008.

ESPÓSITO, A.V. et al. Evaluation of the genotoxic potential of the Hypericum brasiliense (Guttiferae) extract in mammalian cell system in vivo. Genetics and Molecular Biology, v.28, n.1, p.152-5, 2005.

FALKENBERG, M.B. Quinonas. In: SIMÕES, C.M.O. et al. Farmacognosia. 3.ed. Porto Alegre / Florianópolis: Editora Universidade Federal do Rio Grande do Sul e Editora da Universidade Federal de Santa Catarina, 2001. 833p.

FARNSWORTH, N.R.; SOEJARTO, D.D. Global importance of medicinal plants. In: AKERELE, O. et al. (Eds). The conservation of medicinal plants. Cambridge: Cambridge University Press, 1991. p. 25-52. FENNER, R. et al. Antifungal activity of some Brazilian Hypericum species. Phytomedicine: International Journal of Phytotherapy \& Phytopharmacology, v.12, p.236-40, 2005.

FRANÇA, H.S. et al. Atividade antibacteriana de floroglucinóis e do extrato hexânico de Hypericum brasiliense Choysi. Quimica Nova, v.32, n.5, p.1103-6, 2009.

GARAMBONE, E.; ROSA, G. Possíveis benefícios do ácido clorogênico à saúde. Alimentos e Nutrição, v.18, n.2, p.229-35, 2007.

GNERRE, C. et al. Monoamine oxidase inhibitory activity of some Hypericum species native to South Brazil. Journal of Pharmacy and Pharmacology, v.53, p.1273-9, 2001.

KUMAR, A. et al. St. John's Wort (Hypericum perforatum) treatment on restraint stress-induced behavioral and biochemical alteration in mice. BMC Complementary and Alternative Medicine, v.10, p.18-24, 2010.

LORENZI, H.; MATOS, F.J.A. Plantas medicinais do Brasil -Nativas e exóticas. Nova Odessa: Instituto Plantarum, 2002. 560p.

MAKOVETSKAYA, E.Y. Flavonoids of certain species of Hypericum L. Chemistry of Natural Compounds, v.35, p.582-3, 1999.

MANS, D.R.A. et al. Anti-cancer drug discovery and development in Brazil: targeted plant collection as a rational strategy to acquire candidate anti-cancer compounds. The Oncologist, v.5, n.3, p.185-98, 2000. MORAES, I.C.R. Caracterização citogenética e da biologia reprodutiva de três espécies do gênero Hypericum. 2007. 64p. Dissertação (Mestrado em Agricultura Tropical e Subtropical.) - Instituto Agronômico de Campinas, Campinas.

MULINACCI, N. et al. HPLC-DAD and TLC-densitometry for quantification of hypericin in Hypericum perforatum L. extracts. Chromatographia, v.49, p. 197-201, 1999. MURASHIGE, T.; SKOOG, F. A revised medium for rapid growth and bioassays with tobacco tissue cultures. Physiologia Plantarum, v.15, p.473-97, 1962.

NAMLI, S. et al. The effect of different plant hormones (PGRs) on multiple shoots of Hypericum retusum Aucher. Plant Omics Journal, v.3, n.1, p.12-7, 2010.

PRETTO, F.R.; SANTARÉM, E.R. Callus formation and plant regeneration from Hypericum perforatum leaves. Plant Cell, Tissue and Organ Culture, v.62, p.107-13, 2000.

ROBSON, N.K.B. Studies in genus Hypericum L. (Gutiferae) 2. Character of genus. Bulletin of the British Museum (Natural History). Botany, v.8, p.55-226, 1981. ROCHA, L. et al. An antifungal y-pyrone and xanthones with monoamine oxidase inhibitory activity from Hypericum brasiliense. Phytochemistry, v.36, p.1381-5, 1994.

ROCHA, L. et al. Antibacterial phloroglucinols and 
flavonoid from Hypericum brasiliense. Phytochemistry, v.40, p.1447-52, 1995.

SCHEMPP, C.M. et al. St. John's wort (Hypericum perforatum L.). A plant with relevance for dermatology der Hautarzt. Zeitschriftfür Dermatologie, Venerologie, und verwandteGebiete, v.53, n.5, p.316-21, 2002.

SLUSARSKI, S.R. et al. Estudo taxonômico das espécies nativas de Hypericum L. (Hypericaceae) no Estado do Paraná, Brasil. Acta Botanica Brasílica, v.21, p.163-84, 2007.

SUZUKI, O. et al. Inhibition of monoaminooxidase by
Hypericum. Planta Medica, v.50, p.272-4, 1984.

TAKAHASHI, I. et al. Hypericin and pseudohypericin specifically inhibit protein kinase $\mathrm{C}$ : possible relation to their antiretroviral activity. Biochemistry and Biophysics Research Communication, v.165, p.1207-12, 1989.

TRAY, T.S.; KINGSTON, R.L. (Eds.) Toxicology and clinical pharmacology St. John's Wort. 2.ed. Totowa: Humana Press, 2007. 288p.

VUKOVIC-GACIC, B.; SIMIC, D. Identification of natural antimutagens with modulating effects on DNA repair. Basic Life Science, v.61, p.269-77, 1993. 